\title{
Neotropical Monogenoidea. 58. Three new species of Gyrodactylus (Gyrodactylidae) from Scleromystax spp. (Callichthyidae) and the proposal of COII gene as an additional fragment for barcoding gyrodactylids
}

\author{
Marlus Bueno-Silva ${ }^{1,2}$ and Walter A. Boeger ${ }^{1}$ \\ ${ }^{1}$ Laboratório de Ecologia Molecular e Parasitologia Evolutiva, Universidade Federal do Paraná (UFPR), Centro Politécnico, Setor \\ de Ciências Biológicas, Departamento de Zoologia, Curitiba, Paraná, Brazil; \\ ${ }^{2}$ Programa de Pós-Graduação em Zoologia, Universidade Federal do Paraná (UFPR), Setor de Ciências Biológicas, Departamento \\ de Zoologia, Curitiba, Paraná, Brazil
}

\begin{abstract}
Based on molecular markers (COII and ITS1-ITS2) and morphological data, we describe three new Neotropical species of Gyrodactylus von Nordmann, 1832 from Scleromystax barbatus (Quoy et Gaimard) and Scleromystax macropterus (Regan) from southern Brazil. The three new species can be distinguished from each other by sequences of both molecular markers and morphology of hooks and anchors. Gyrodactylus bueni sp. n. is characterised by having hook with shaft curved, heel straight, shelf straight, toe pointed, anchor with superficial root slender, elongate and male copulatory organ armed with two rows of spinelets. Gyrodactylus major sp. n. presents hook with shaft, point curved, proximal shaft straight, heel convex, shelf convex, toe concave, anchor with superficial root robust and male copulatory organ armed with two rows of spinelets. Gyrodactylus scleromystaci sp. n. presents hook with shaft, point recurved, heel convex, shelf convex, toe pointed, anchor with superficial root curved and male copulatory organ armed with two rows of spinelets. These species appear to be closely related to other species of Gyrodactylus known from other species of Callichthyidae. These new species, however, differ by the comparative morphology of the haptoral hard structures and molecular data. Comparative analysis of sequences from these species of Gyrodactylus suggests that the COII gene may represent an important marker for the taxonomy of species of Gyrodactylidae and, perhaps, for species of other lineages of Monogenoidea.
\end{abstract}

Keywords: DNA barcoding, taxonomy, mitochondrial marker, morphology, ITS, Siluriformes, Brazil

Members of Gyrodactylidae (Monogenoidea) are ectoparasites known mainly from bony fishes. Oviparous gyrodactylids are restricted to South American freshwater catfishes, whereas viviparous gyrodactylids represent one of the most diverse and widespread taxon of Monogenoidea (Boeger et al. 2003, Bakke et al. 2007), with more than 400 species described worldwide (Harris et al. 2008). In the Neotropical region, approximately 20 species of Gyrodactylus von Nordmann, 1832 are presently known (Boeger et al. 2006, Cohen and Kohn 2008). In South America, more than 10 species of Gyrodactylus are known from bony fishes (Kohn and Cohen 1998, Cohen and Kohn 2008), of which four species are known from callichthyid catfishes in Brazil (Boeger et al. 2006, Bueno-Silva and Boeger 2009).

The identification of the viviparous gyrodactylids is essentially based on the morphology of the haptoral structures. Nevertheless, it has been demonstrated that the haptoral hard parts show a high degree of variation in size and shape according to biotic and abiotic environmental conditions (Malmberg 1970, Mo 1991a,b, Harris 1998, Geets et al. 1999, Dmitrieva and Dimitrov 2002, Huyse and Volckaert 2002, Dávidová et al. 2005, Olstad et al. 2009, Bueno-Silva et al. 2011), which could hinder species delimitation. Part of this problem has been solved with the use of DNA molecular markers, which have been fundamental also for studies on the taxonomy, ecology and phylogeny of gyrodactylids (Cunningham and Mo 1997, Matějusová et al. 2001, Huyse and Volckaert 2002, Ziętara and Lumme 2003, Meinilä et al. 2004, Hansen et al. 2007a, Bueno-Silva et al. 2011).

Viviparous gyrodactylids are increasingly reported as pathogens of wild and farmed fish. The notoriety of the epidemic species, such as Gyrodactylus salaris Malmberg, 1957, has stimulated research on the development of molecular markers to distinguish pathogenic from nonpathogenic species (Cunningham et al. 1995a,b, Cunningham and Mo 1997, Meinilä et al. 2002). Although molecular markers of rDNA (mostly Internal Transcribed Spacers, ITS) have contributed to discrimination of gy- 
rodactylid species (Cunningham et al. 1995a, Cunningham 1997), sequencing of mitochondrial gene has been important in the determination of lineages within species of Gyrodactylus (Meinilä et al. 2004, Hansen et al. 2007b, Bueno-Silva et al. 2011).

The COI gene is most commonly used for the barcoding of eukaryotes (Hebert et al. 2003), but the available primers for amplifying cytochrome oxidase I (COI) gene of Gyrodactylus spp. seem to work only on a limited number of species, apparently because of interspecific molecular variability (Meinilä et al. 2002). Since the mitochondrial DNA is a suitable marker for the detection of evolutionary lineages of Gyrodactylus (see Meinilä et al. 2002, 2004, Hansen et al. 2003, 2007a,b), but of difficult amplification, we propose a fragment of the cytochrome oxidase II (COII) gene as an additional marker for barcoding viviparous gyrodactylids.

The COII gene has been successfully used as molecular marker in phylogenetic inference and evolutionary studies for various species of animals (Caterino and Sperling 1999, Pruess et al. 2000, Piaggio and Spicer 2001, Rawson and Burton 2006). Although the mitochondrial genome has been sequenced for a few species of Gyrodactylus (Huyse et al. 2007, 2008, Plaisance et al. 2007), this study proposes, for the first time, to use the COII gene as a marker for gyrodactylids.

In the present study, we describe three new Neotropical species of Gyrodactylus from two sympatric host species, Scleromystax barbatus (Quoy et Gaimard) and Scleromystax macropterus (Regan), which are found in coastal drainages of southeastern Brazil (Ferraris 2007). The support for these species is derived from a combination of traditional morphological analysis and molecular markers of DNA (COII and ITS1-ITS2). These gyrodactylids represent the first species of Gyrodactylus described from species of Scleromystax Günther.

\section{MATERIALS AND METHODS}

Adult specimens of Scleromystax barbatus $(\mathrm{n}=107)$ and S. macropterus $(\mathrm{n}=34)$ were collected between 2007 and 2010 from coastal drainages of two sub-basins of the Paranaguá basin, state of Paraná, southeastern Brazil: Fortuna River, municipality of Pontal do Paraná; Ribeirão River, municipality of Paranaguá; Pinto River and Marumbi River, municipality of Morretes. Specimens of Corydoras ehrhardti Steindachner and Corydoras paleatus (Jenyns) were collected in 2006 from the Miringuava River, municipality of São José dos Pinhais, state of Paraná, southern Brazil.

Fish were captured by electrofishing, sacrificed by pithing and placed in vials containing warm water $\left(60^{\circ} \mathrm{C}\right)$ for a few seconds before being fixed in $95 \%$ ethanol or $5 \%$ formalin. Specimens of Gyrodactylus were removed from ethanol under a dissecting microscope and the haptor excised and mounted on a slide prepared with Hoyer's mounting medium. The parasite trunk was used for DNA extraction. Haptoral structures of all parasites were photographed with a digital camera (Olympus QColor 5) connected to a phase contrast microscope (Olympus
BX 51), and the images were used to obtain the measurements of the haptoral sclerites. Measurements, all in micrometres, were made following the procedures of Kritsky et al. (1995) and Popazoglo and Boeger (2000).

The pairs of primers of a fragment of the COII gene were designed with the help of the software Primer Premier 5.0 (Premier Biosoft International) by aligning available mitochondrial sequences of Monogenoidea from GenBank: Gyrodactylus derjavinoides Malmberg, Collins, Cunningham et Jalali, 2007 (accession number EU293891), Gyrodactylus thymalli Žitňan, 1960 (EF527269), G. salaris (DQ988931), and Microcotyle sebastis Goto, 1894 (DQ412044). Four primers, of which three are degenerated, were designed in the following manner: $\operatorname{cox} 2 \mathrm{~F}$ (5'-TACAYAYCGCCCGTCAAYYTCG-3'), cox2R (5'-AATAMWKATWGGCATRWAAGARTG-3'), cox2F2 (5'TTTCACTGAGATAAGTCGTAAC-3') and cox2R2 (5'-TTACCGCTTCCYTGAACACG-3'). Further, an alternative internal reverse primer was designed to amplify some DNA samples of oviparous gyrodactylids: cox2Rint (5'-CATAATTCTCTACARTARCC-3').

Total DNA was extracted using the DNeasy Tissue kit (Qiagen, Venlo, Netherlands). The polymerase chain reaction (PCR) mix for amplification of the COII gene was optimized as follows: $3 \mu 1$ DNA template (15-30 ng), $0.4 \mathrm{mM}$ dNTP, $3 \mathrm{mM} \mathrm{MgCl}$, 1 U Platinum Taq polymerase (Invitrogen, Waltham, USA), $1 \times$ PCR-buffer (Invitrogen), 0.4 pmol each primer and autoclaved water to complete $25 \mu \mathrm{l}$ final volume. The PCR program used in this amplification was optimized as follows: $5 \mathrm{~min}$ at $95^{\circ} \mathrm{C}$, after which 40 cycles of $30 \mathrm{~s}$ at $94^{\circ} \mathrm{C}, 45 \mathrm{~s}$ at $42-50{ }^{\circ} \mathrm{C}$ (gradient), $45 \mathrm{~s}$ at $72{ }^{\circ} \mathrm{C}$, and finally $4 \mathrm{~min}$ at $72^{\circ} \mathrm{C}$.

Fifteen DNA samples of three species of Neotropical Gy rodactylus that amplified with the COII primers (Gyrodactylus corydori Bueno-Silva et Boeger, 2009, Gyrodactylus samirae Popazoglo et Boeger, 2000), and Gyrodactylus superbus (Szidat, 1973) were used with primers of the COI gene for comparison purposes. Two combinations of primers (ZMO1-HB and LBHB - Meinilä et al. 2002, Hansen et al. 2003) were used to attempt amplification of the COI gene since these had been shown previously to work for Neotropical species of Gyrodactylus (see Bueno-Silva et al. 2011).

All possible combinations of COI primers from Meinilä et al. (2002) and Hansen et al. (2003) were tested. The PCR mix for COI gene was composed by $5 \mu 1$ DNA template, $0.5 \mathrm{mM}$ dNTP, $4 \mathrm{mM} \mathrm{MgCl}$, 1 U Platinum Taq polymerase (Invitrogen), $1 \times$ PCR-buffer (Invitrogen), 0.5 pmol each primer and autoclaved water to complete $25 \mu \mathrm{l}$ final volume. The PCR program for amplification of the COI fragment followed Bueno-Silva et al. (2011): $5 \mathrm{~min}$ at $95^{\circ} \mathrm{C}$, then 40 cycles of $1 \mathrm{~min}$ at $94^{\circ} \mathrm{C}$, $1 \mathrm{~min}$ at $45-50{ }^{\circ} \mathrm{C}$ (gradient), $2 \mathrm{~min}$ at $74^{\circ} \mathrm{C}$, and finally $7 \mathrm{~min}$ at $74^{\circ} \mathrm{C}$. Cytochrome oxidase I amplicons were not sequenced.

Confirmation of the identification of the new species of Gyrodactylus was supported also by comparative analysis of the fragment stretching from internal transcribed spacer 1 (ITS1)-internal transcribed spacer 2 (ITS2). The primers ITS1 (5'-TTTCCGTAGGTGAACCT-3') and ITS2 (5'-GGTAATCACGCTTGAATC-3') (Ziętara et al. 2000) were used to amplify a fragment of approximately $1200 \mathrm{bp}$ of the ITS1-5.8SITS2. The PCR program for ITS was as follows: $5 \mathrm{~min}$ at $95^{\circ} \mathrm{C}$, followed by 40 cycles of $1 \mathrm{~min}$ at $95^{\circ} \mathrm{C}, 45 \mathrm{~s}$ at $50^{\circ} \mathrm{C}, 1 \mathrm{~min}$ at $72^{\circ} \mathrm{C}$, and finally $5 \mathrm{~min}$ at $72^{\circ} \mathrm{C}$. Each amplification reaction contained 3-5 $\mu \mathrm{l}$ of template DNA, $3 \mathrm{mM} \mathrm{MgCl}, 1 \times$ PCR-buffer 
(Invitrogen), 0.5 pmol each primer, $0.4 \mathrm{mM}$ dNTP and $1 \mathrm{U}$ Platinum Taq polymerase (Invitrogen) in a total volume of $25 \mu \mathrm{l}$. All PCR products were electrophoresed in a 1.5\% agarose gel and purified using MinElute Purification kit (Qiagen). Sequencing was performed using BigDye 3.1 Chemistry in a 3130 Genetic Analyzer (Applied Biosystems, Waltham, USA).

Sequences were edited using the Staden Package 2.0 (Bonfield et al. 1995) and aligned using MUSCLE (Edgar 2004). Obtained sequences of COII and ITS of Gyrodactylus were deposited in GenBank under accession numbers: G. corydori (KF751714KF751716), G. samirae (GU131200, KF751717, KF751718), and G. superbus (GU131202-GU131204). Accession numbers of DNA sequences of the new species of Gyrodactylus are presented in their respective descriptions. Two sequences of COII (KF751723) and ITS1-ITS2 (KF767471) of Aglaiogyrodactylus ctenistus Kritsky, Vianna et Boeger, 2007 were used as an outgroup.

Species delimitations were inferred by Neighbor-Joining (NJ) method implemented in PAUP 4.0b10 (Swofford 2001) based on the COII and ITS sequences, using the PaupUp interface (Calendini and Martin 2005). Bootstrap values (1000 pseudoreplicates) were used to assess branch support. The software jModelTest 1.1 (Posada 2008) was used to select the most appropriate model of DNA evolution for COII (TPM1uf + I) and ITS1-ITS2 (TVM+'I). Phylograms were viewed and edited using Dendroscope 3.2 (Huson and Scornavacca 2012). Sequences of the species of Gyrodactylus from Corydoras ehrhardti and C. paleatus were used in these analyses to test the molecular support for the new species.

Mean divergence of differences in the nucleotide composition of COII between and within species of Gyrodactylus was calculated by using the Tamura-Nei model implemented in MEGA 5.2 (Tamura et al. 2011). The estimation of variance was performed by using the bootstrap method (1000 pseudoreplicates) implemented in MEGA.

Types were deposited in the following institutions, as indicated in respective descriptions: Institute of Parasitology, Academy of Sciences of the Czech Republic, Czech Republic (IPCAS); Museu de Zoologia da Universidade de São Paulo, Brazil (MZUSP); Museum National d'Histoire Naturelle, Paris, France (MNHN); and Harold W. Manter Laboratory, University of Nebraska, Lincoln, USA (HWML).

\section{RESULTS}

Four new Neotropical species of Gyrodactylus were recovered from the body surface of Scleromystax barbatus and S. macropterus (Figs. 1-23). A limited number of one of these new parasite species $(n=5)$, however, precluded its description herein. Nevertheless, some individuals of this rare species, Gyrodactylus sp. (Figs. 22, 23), were sequenced and are analysed herein (KF751710-KF751713, KF767481-KF767483). From Corydoras ehrhardti and C. paleatus, three known species of Gyrodactylus have been recovered: G. corydori, G. samirae and G. superbus.

Class Monogenoidea Bychowsky, 1937

Subclass Polyonchoinea Bychowsky, 1937

Order Gyrodactylidea Bychowsky, 1937
Gyrodactylidae van Beneden et Hesse, 1863

Gyrodactylus bueni sp. n.

Figs. 1, 4-7, 18, 19

Description (based on holotype and 17 paratypes). Body elongate, 368 (293-453; $\mathrm{n}=7$ ) long, 73 (41-97; $\mathrm{n}=7$ ) wide. Cephalic glands, head organs, spike sensilla conspicuous. Cephalic glands anterolateral, lateral, posterolateral to pharynx. Distal pharyngeal bulb muscular, 30 $(21-38 ; \mathrm{n}=3)$ wide; proximal pharyngeal bulb glandular, $33(23-42 ; n=3)$ wide. Caeca non-confluent. Male copulatory organ $14(12-16 ; n=6)$ wide, armed with 1 spine, 2 rows of spinelets; external row with 3-4 large spinelets; internal row with 2-3 small spinelets. Testis ovate, 24 $(15-32 ; n=5)$ wide, posterior to germarium.

Germarium ovate, 23 (20-26; $\mathrm{n}=2)$ long, 37 (36-37; $\mathrm{n}=2$ ) wide. Uterus with up to 2 generations of embryos. Anchor 55 (53-57; $\mathrm{n}=7)$ long, shaft $32(30-35 ; \mathrm{n}=7)$ long, straight point $17(16-18 ; \mathrm{n}=7)$, deep root poorly developed, knob-like, superficial root elongate, slender. Hook with shaft curved, heel straight, shelf straight, toe pointed, shank $17(16-17 ; \mathrm{n}=6)$ long; hooklet 10 (9-10; $\mathrm{n}=6$ ) long; loop of filament hooklet about $1 / 2$ of shank length. Deep bar $2(1-3 ; n=3)$ long. Superficial bar 23 $(20-26 ; n=4)$ wide, $10(10-11 ; n=4)$ long, with 2 anterolateral projections; shield trapezoidal to triangular.

Type host: Scleromystax macropterus (Regan) (Siluriformes: Callichthyidae).

O the r h o st: Scleromystax barbatus (Quoy et Gaimard) (Siluriformes: Callichthyidae).

Type locality: Fortuna River, Pontal do Paraná, Paraná, Brazil (25³9'54"S; 48³1'05"W).

Site of infection: Body surface.

Specimens studied: Holotype, HWML 49890; 3 paratypes, HWML 49887-49889; 3 paratypes, IPCAS M-546; 5 paratypes, MNHN HEL364-HEL368; 6 paratypes, MZUSP 7493-7498.

Specimens sequenced: COII (GU131212, GU131213, KF751721 and KF751722); ITS (KF767475-KF767477).

Etymology: The specific name is homage to the parents of M. Bueno-Silva (Antonio Bueno and Rute Bueno).

Remarks. The new species can be distinguished from other known Neotropical species of Gyrodactylus from callichthyid catfishes by the comparative morphology of the hard structures of the haptor. Gyrodactylus bueni presents hooks and anchors morphologically similar to those of G. anisopharynx Popazoglo et Boeger, 2000 and $G$. superbus, respectively. The new species, however, can be differentiated from G. anisopharynx by the shape of the hooks with heel straight (hooks with heel convex in G. anisopharynx) and anchors with superficial root comparatively more slender, elongate (anchors with superficial root robust and comparatively shorter in $G$. anisopharynx).

Gyrodactylus bueni can be distinguished from G. superbus by presenting hooks with shaft relatively shorter, 

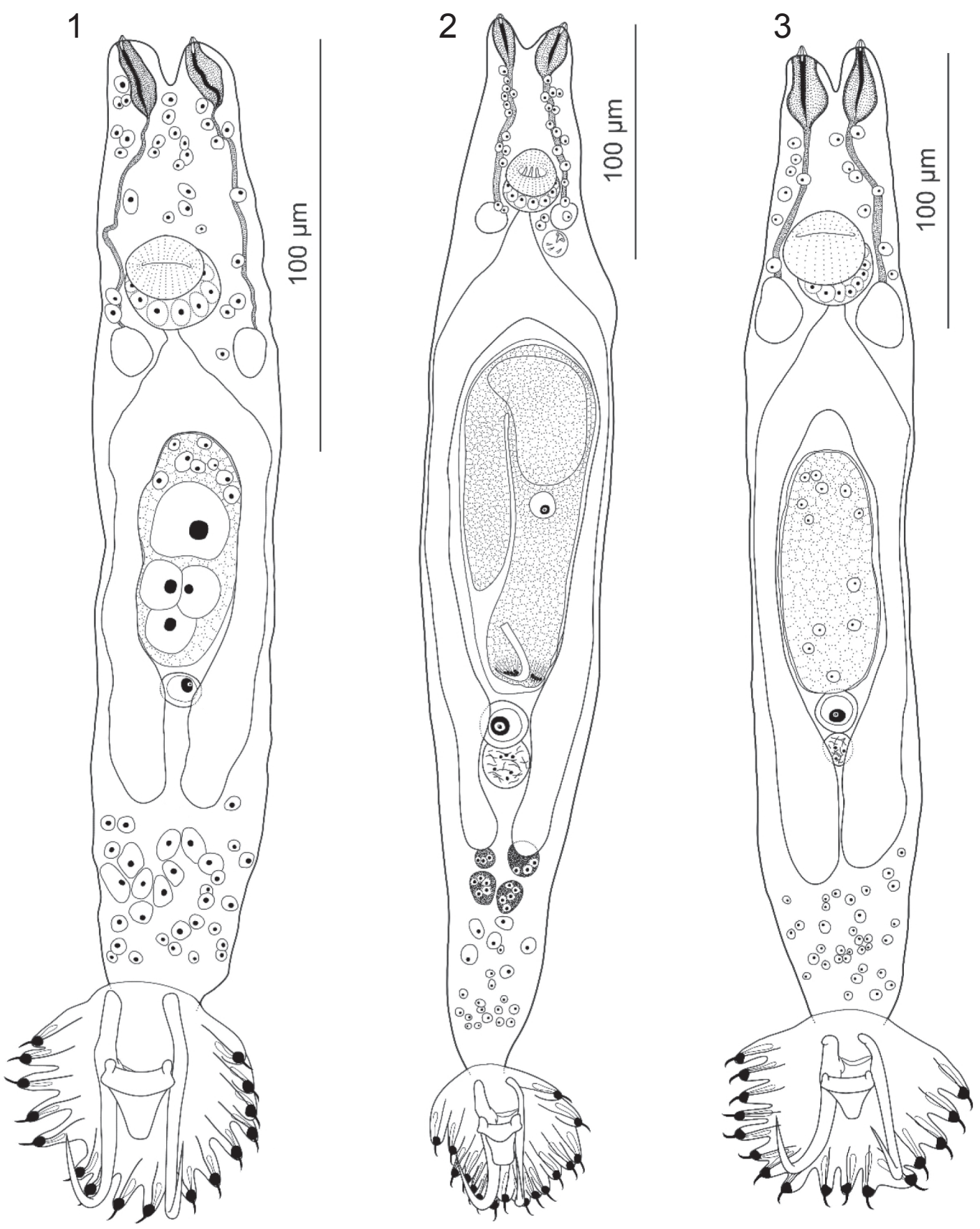

Figs. 1-3. Whole-mounted specimens (holotypes) of three new species of Gyrodactylus from Scleromystax macropterus and S. barbatus (ventral view). Fig. 1. Gyrodactylus bueni sp. n. Fig. 2. Gyrodactylus major sp. n. Fig. 3. Gyrodactylus scleromystaci sp. n.

heel straight, toe pointed (hooks with heel convex and depressed toe in G. superbus); anchors with superficial root relatively shorter (anchors with superficial root and point longer in G. superbus) and superficial bar with two anterolateral projections (lacking in G. superbus).

From $G$. samirae, the new species differs by having hooks with shaft curved, toe pointed, heel straight, and anchors with superficial root slender (hooks with shaft straight, truncate toe, heel trapezoidal, and anchors with superficial root relatively shorter in G. samirae).

\section{Gyrodactylus major sp. n.}

Figs. 2, 8-11, 16, 17

Description (based on holotype and 16 paratypes). Body elongate, 524 (469-582; $\mathrm{n}=10)$ long, 93 (63-122; $\mathrm{n}=10)$ wide. Cephalic glands, head organs, spike sensilla conspicuous. Cephalic glands anterolateral, lateral and posterolateral to pharynx. Distal pharyngeal bulb muscular, 35 (22-43; $\mathrm{n}=7)$ wide; digitiform projections of distal pharyngeal distinct; proximal pharyngeal bulb glandular, 40 (31-47; $\mathrm{n}=7)$ wide. Caeca non-confluent. Male copulatory organ $17(15-18 ; \mathrm{n}=7)$ wide, armed 

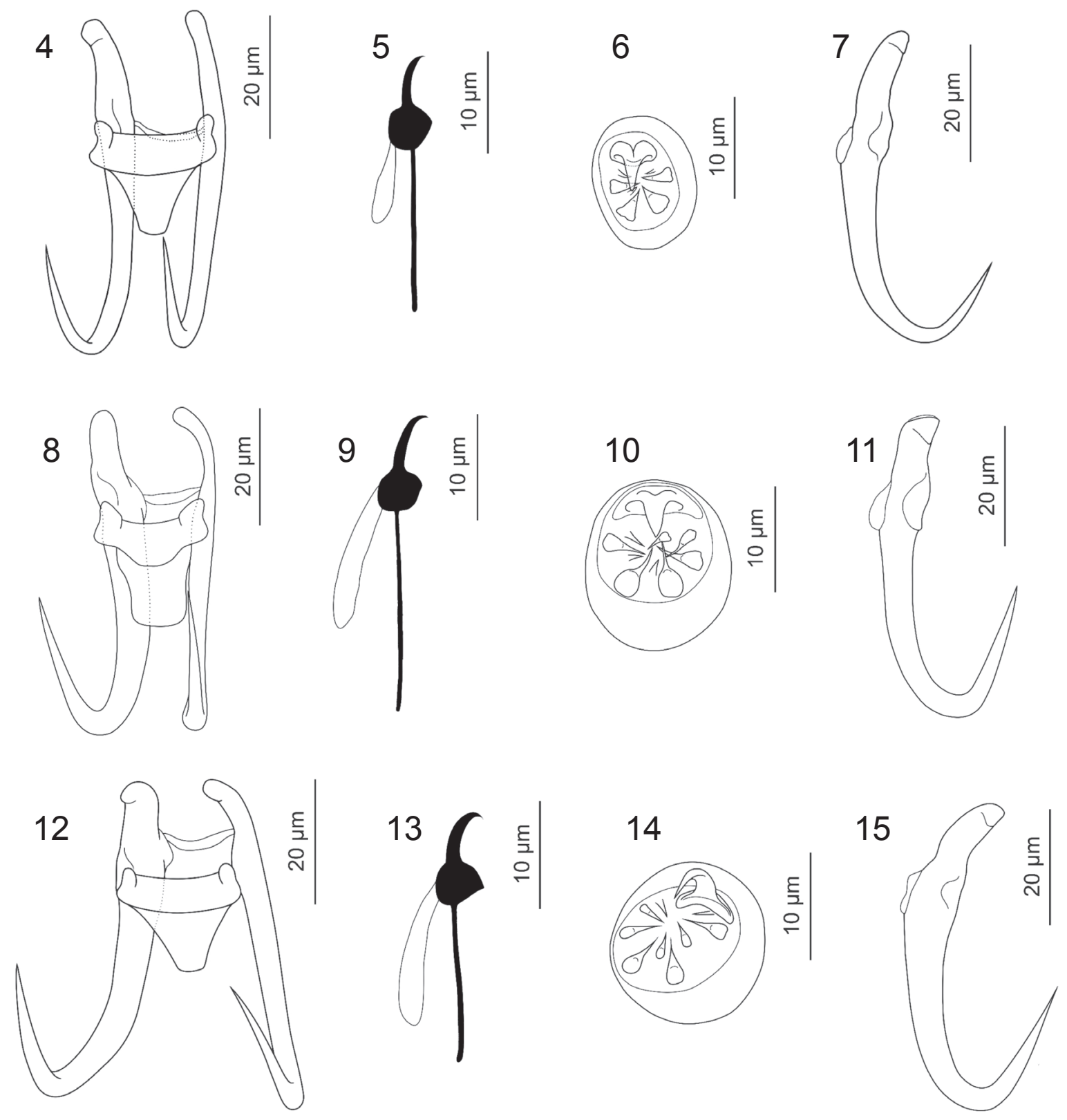

Figs. 4-15. Gyrodactylus bueni sp. n. (Figs. 4-7), Gyrodactylus major sp. n. (Figs. 8-11) and Gyrodactylus scleromystaci sp. n. (Figs. 12-15) from Scleromystax barbatus and S. macropterus. Figs. 4, 8, 12. Anchors, deep bar and superficial bar. Figs. 5, 9, 13. Hook. Figs. 6, 10, 14. Male copulatory organ (MCO). Figs. 7, 11, 15. Anchor.

with 1 spine, 2 rows of spinelets; external row with 5-7 large spinelets; internal row with 4-6 small spinelets. Testis ovate $22(18-31 ; \mathrm{n}=3)$ wide, posterior to germarium.

Germarium ovate, 25 (22-36; $\mathrm{n}=9$ ) long, 32 (19-44; $\mathrm{n}=9$ ) wide. Uterus with up to 2 generations of embryos. Anchor 55 (54-56; n = 8) long, shaft 34 (33-36; $\mathrm{n}=8)$ long, straight point $21(20-23 ; \mathrm{n}=8)$, deep root poorly developed, knob-like, superficial root robust. Hook with shaft, point curved, proximal shaft straight, heel convex, shelf convex, toe concave, shank 20 (19-21; $\mathrm{n}=7$ ) long; hooklet $10(9-10 ; \mathrm{n}=7)$ long; filamentous hooklet $(\mathrm{FH})$ loop about $2 / 3$ of shank length. Deep bar $3(3-4 ; n=10)$ long. Superficial bar $27(21-34 ; \mathrm{n}=4)$ wide, $8(7-10$; $\mathrm{n}=4$ ) long, with 2 anterolateral projections; shield trapezoidal.

Type host: Scleromystax macropterus (Regan) (Siluriformes: Callichthyidae).

Other host: Scleromystax barbatus (Quoy et Gaimard) (Siluriformes: Callichthyidae).

Type locality: Fortuna River, Pontal do Paraná, Paraná, Brazil (2539'54"S; 48³1'05"W).

Site of infection: Body surface.

Specimens studied: Holotype, HWML 49886; 3 paratypes, HWML 49883-49885; 2 paratypes, IPCAS M-545; 5 paratypes, MNHN HEL359-HEL363; 6 paratypes, MZUSP 7487-7492. 

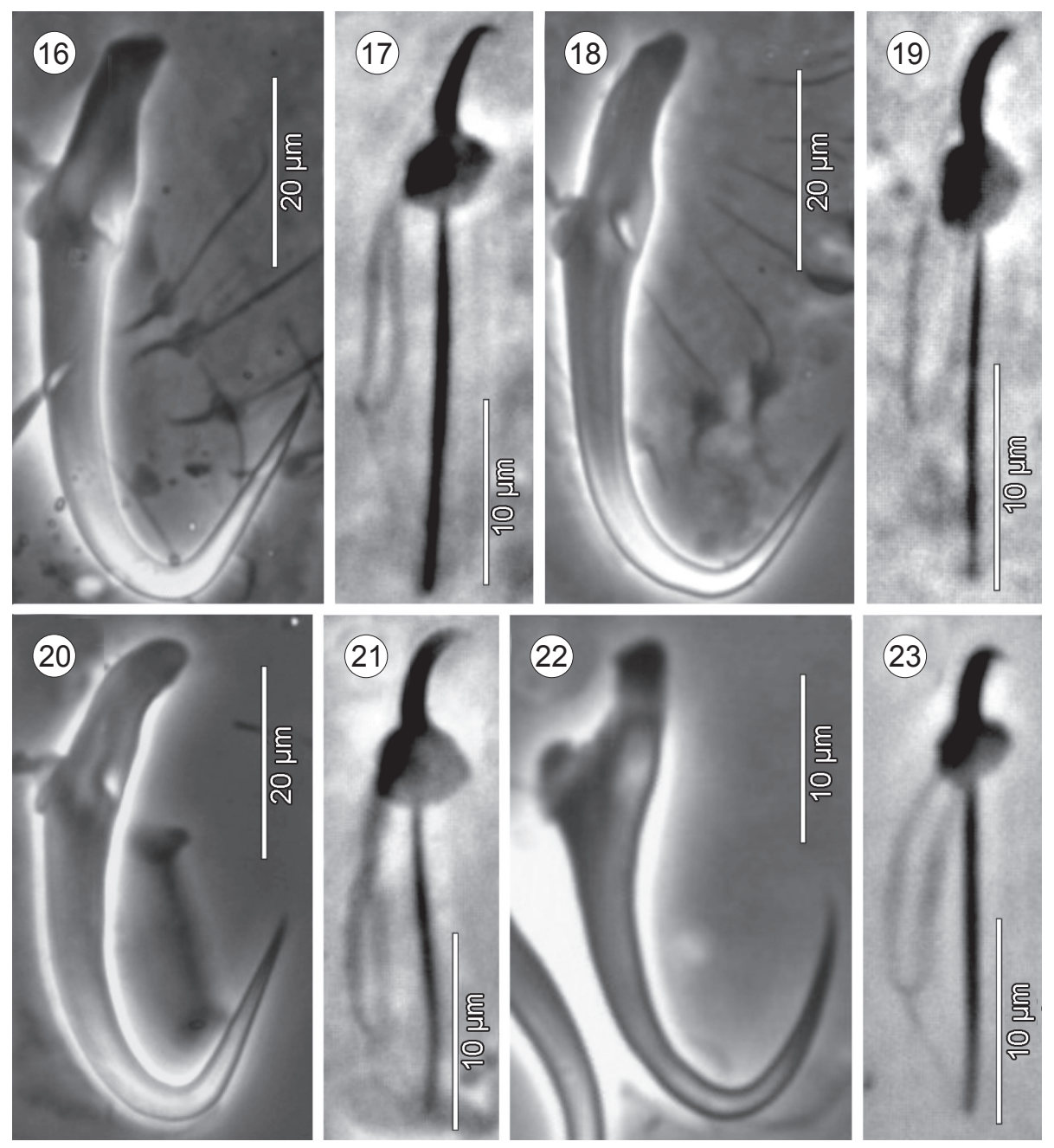

Figs. 16-23. Gyrodactylus major sp. n. (Figs. 16, 17), Gyrodactylus bueni sp. n. (Figs. 18, 19), Gyrodactylus scleromystaci sp. n. (Figs. 20,21) and Gyrodactylus sp. from Scleromystax macropterus and S. barbatus. Figs. 16, 18, 20, 22. Anchor. Fig. 17, 19, 21, 23. Hook.

Specimens sequenced: COII (GU131207, GU131208, KF751719 and KF751720); ITS (KF767478-KF767480).

E t y mology: The specific epithet is from Latin and refers to the large body size of the specimens, which is uncommon in Neotropical species of Gyrodactylus.

Remarks. Gyrodactylus major can be distinguished from other syntopic Neotropical species of Gyrodactylus described above (G. bueni) by the morphology of the hooks with heel convex, shelf convex and toe concave (hooks with heel straight, shelf straight, toe pointed in G. bueni) and anchors with superficial root robust (anchors with superficial root slender, elongate in G. bueni).

Further, G. major can be differentiated from other known Neotropical species of Gyrodactylus from callichthyid catfishes by the comparative morphology of the hooks and anchors. From G. anisopharynx, the new species differs by the general shape of the hooks with shelf convex and toe concave (hooks with shelf straight, toe pointed in G. anisopharynx). Gyrodactylus major differs from $G$. corydori by possessing hooks with shaft curved and proximal shaft straight (hooks with shaft straight in G. corydori), and from G. superbus by having hooks with shelf convex and anchor with superficial root robust (hooks with shaft comparatively longer, shelf straight, and anchors with superficial root slender, elongate in $G$. superbus). The characteristics that allow distinction of the new species from $G$. samirae are: hooks with shaft curved, proximal shaft straight, toe concave, heel convex (hooks with shaft straight, truncate toe, heel trapezoidal, and anchor with superficial root relatively shorter in G. samirae).

Gyrodactylus scleromystaci sp. n. Figs. 3, 12-15, 20, 21

Description (based on holotype and 14 paratypes). Body elongate, 367 (321-396; $\mathrm{n}=5)$ long, 76 (52-95; $\mathrm{n}=5$ ) wide. Cephalic glands, head organs, spike sensilla conspicuous. Cephalic glands anterolateral, lateral and posterolateral to pharynx. Distal pharyngeal bulb muscular, $40(33-49 ; \mathrm{n}=4)$ wide; proximal pharyngeal bulb 
glandular $41(35-53 ; \mathrm{n}=4)$ wide. Caeca non-confluent. Male copulatory organ $16(14-18 ; n=3)$ wide, armed with 1 spine, 2 rows of spinelets; external row with 5-7 large spinelets; internal row with $4-5$ small spinelets. Testis ovate $20(13-28 ; n=2)$ wide, posterior to germarium.

Germarium ovate, $26(21-31 ; n=4)$ long, 36 (23-50; $\mathrm{n}=4$ ) wide. Uterus with up to 2 generations of embryos. Anchor $49(47-51 ; \mathrm{n}=13)$ long, shaft $29(28-31 ; \mathrm{n}=13)$ long, straight point $19(17-21 ; \mathrm{n}=13)$, deep root poorly developed, knob-like, superficial root curved. Hook with shaft, point recurved, heel convex, shelf convex, toe pointed, shank $15(14-16 ; \mathrm{n}=13)$ long; hooklet $9(8-10$; $\mathrm{n}=13$ ) long; FH loop about $3 / 4$ of shank length. Deep bar $3(2-3 ; n=6)$ long. Superficial bar $26(20-39 ; n=6)$ wide, $12(8-14 ; \mathrm{n}=6)$ long, with 2 anterolateral projections; shield trapezoidal.

Type host: Scleromystax barbatus (Quoy et Gaimard) (Siluriformes: Callichthyidae).

Other host: Scleromystax macropterus (Regan) (Siluriformes: Callichthyidae).

Type locality: Marumbi River, Morretes, Paraná, Brazil (2530'54"S; 4852'03"W).

Other localities: Pinto River, Morretes, Paraná, Brazil (2530'50"S; 4850'34"W); Ribeirão River, Paranaguá, Paraná, Brazil $\left(25^{\circ} 36^{\prime} 02^{\prime \prime S}\right.$; 48 $\left.37^{\circ} 19^{\prime \prime W}\right)$; Fortuna River, Pontal do Paraná, Paraná, Brazil (2539'54"S; 48³1'05"W).

Site of infection: Body surface.

Specimens studied: holotype, HWML 49894; 3 paratypes, HWML 49891-49893; 2 paratypes, IPCAS M-547; 4 paratypes, MNHN HEL369-HEL372; 5 paratypes, MZUSP 7499-7503.

Specimens sequenced: COII (GU131216, GU131217, GU131220 and KF751709); ITS (KF767472-KF767474).

E t y m o log y: The specific epithet is from Greek and refers to the hosts (species of Scleromystax).

Remarks. Gyrodactylus scleromystaci can be distinguished from other syntopic Neotropical species of Gyrodactylus described above (G. bueni and G. major). From $G$. bueni, the new species differs by the shape of the hooks with heel convex and shelf convex (hooks with heel straight and shelf straight in G. bueni), and anchors with superficial root curved (anchors with superficial root slender and relatively longer in G. bueni). From G. major, G. scleromystaci differs by having hooks with shaft comparatively thicker, point recurved and toe pointed (hooks with proximal shaft straight and toe concave in G. major).

Gyrodactylus scleromystaci presents hooks morphologically similar to G. corydori. Nevertheless, the new species can be distinguished from G. corydori by having hooks with toe pointed and shaft curved (hooks with toe concave and shaft straight in G. corydori). Moreover, G. scleromystaci can be distinguished from other known Neotropical species of Gyrodactylus from callichthyid catfishes by the comparative morphology of the hooks and anchors. From G. anisopharynx, the new species can be differentiated by presenting hooks with shelf convex, point recurved and anchors with superficial root curved (hook with shelf straight and anchor with superficial root robust in G. anisopharynx). Gyrodactylus scleromystaci differs from $G$. superbus by presenting hooks with shelf convex, toe pointed and anchors with superficial root curved (hooks with shaft relatively longer, shelf straight, depressed toe and anchors with superficial root elongate in G. superbus) and from G. samirae by having hooks with shaft curved, toe pointed, heel convex and anchors with superficial root curved (hooks with shaft straight, truncate toe, heel trapezoidal and anchors with superficial root comparatively shorter in G. samirae).

\section{Molecular data}

A total of 37 sequences of Gyrodactylus were obtained, of which 25 were sequences of COII and 12 sequences of ITS. Only three out of 15 tissue samples of Neotropical Gyrodactylus amplified a fragment of COI gene (one sample of G. corydori and two samples of G. superbus). Only two COI primer pairs (ZMO1-HB and LB-HB) were positive, but no amplicons were obtained with all other possible combinations of COI primers. The primers of COI amplified this fragment adequately only for few samples $(n=3)$. For the remaining samples, the use of these primer pairs resulted in no amplicons or unspecific amplifications.

The primers for the fragment of COII were positive for all samples analysed and resulted in high quality sequences of 564-576 bp. All COII sequences of Gyrodactylus obtained herein present TTG start codon and TAA or TAG as stop codons. The TTG start codon is a novelty for the COII gene of Gyrodactylus spp. On the other hand, specimens of oviparous gyrodactylids have an ATG start codon and TAA stop codon for this gene.

The resulting NJ phylogram based on the fragment of COII (Fig. 24) indicates the potential of this fragment as a useful molecular marker for barcoding species of Gyrodactylus and possibly other members of Gyrodactylidae. Both phylogenetic reconstructions of the COII and ITS sequences showed clades of species that coincided with previous morphology-based identification and presented high bootstrap values (100\%) (Fig. 25). Further, mean divergence of COII, calculated as the percentage of differences in the nucleotide composition, between the species clades varied from $16 \%$ to $72 \%$ (Table 1). In contrast, intraspecific variation of COII sequences of Gyrodactylus varied from $0 \%$ to $3 \%$ (Table 1 ).

\section{DISCUSSION}

Morphologic differences found between anchors and hooks allowed the identification of three new Neotropical species of Gyrodactylus from the body surface of Scleromystax barbatus and $S$. macropterus in southern Brazil. The identification of these new species was greatly sup- 


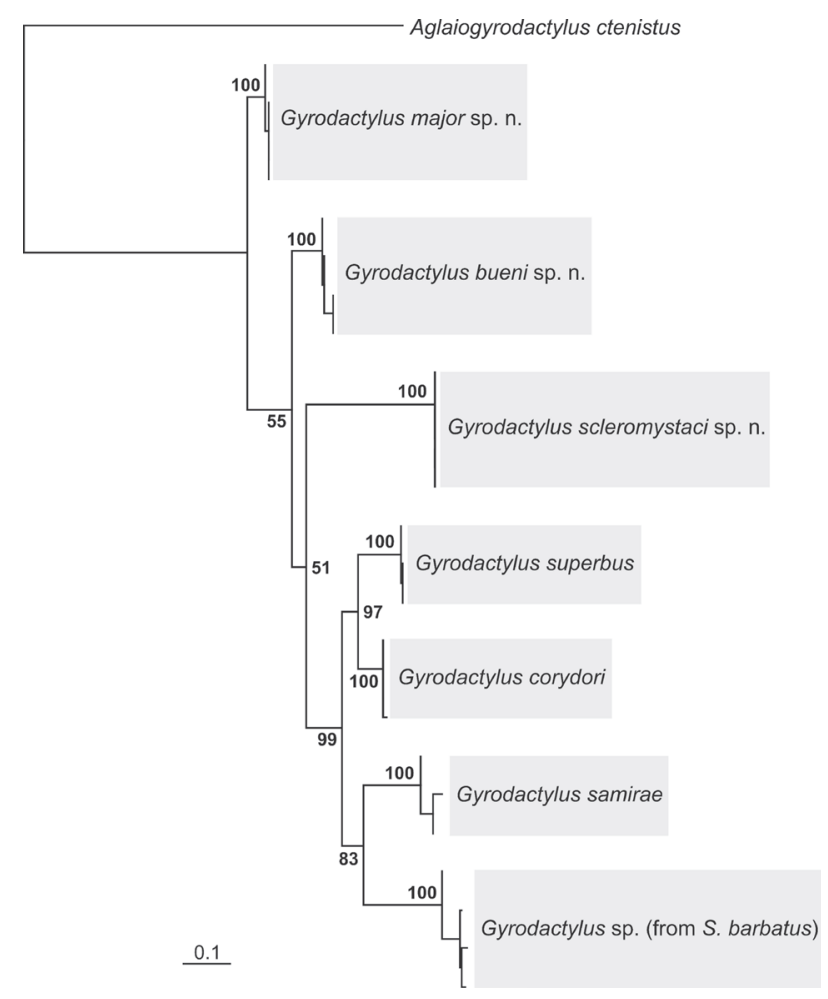

Fig. 24. Rooted phylogram from Neighbor-Joining (NJ) analysis based on the mitochondrial cytochrome oxidase II (COII) gene from seven Neotropical species of Gyrodactylus (a total of 25 sequences). Branch support was obtained under bootstrap (1000 pseudoreplicates).

\section{ITS1-ITS2}

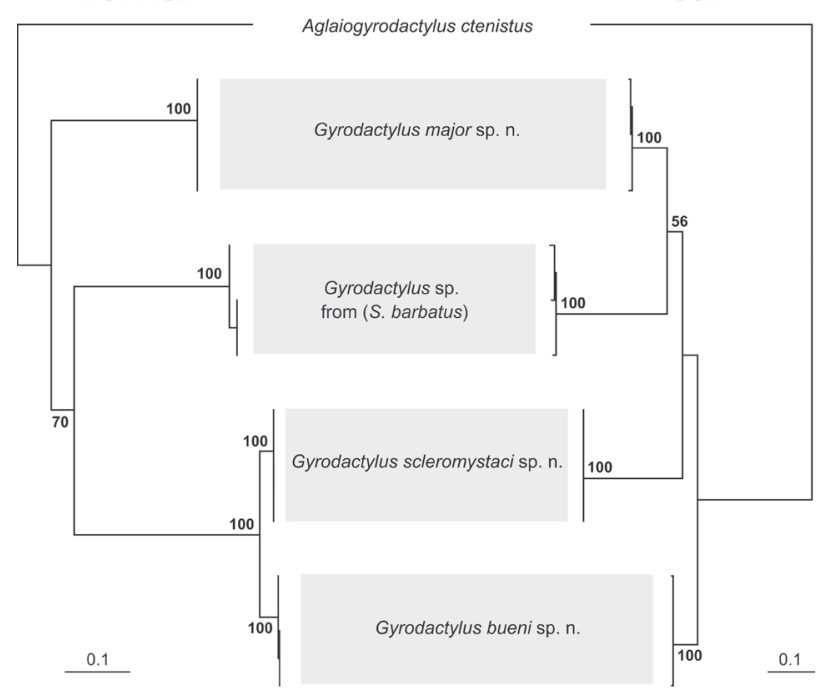

Fig. 25. Rooted phylograms from Neighbor-Joining (NJ) analysis based on the internal transcribed spacer 1 (ITS1)- internal transcribed spacer 2 (ITS2) (12 sequences) and the mitochondrial cytochrome oxidase II (COII) gene (12 sequences) of four Neotropical species of Gyrodactylus found on Scleromystax barbatus and Scleromystax macropterus. Branch support was obtained under bootstrap (1 000 pseudoreplicates).
Table 1. Mean divergence, calculated as the percentage of differences in the nucleotide composition, between COII sequences of Neotropical species of Gyrodactylus (Tamura-Nei model). Values of intraspecific variation of COII are underlined.

\begin{tabular}{|c|c|c|c|c|c|c|}
\hline Species & 2 & 3 & 4 & 5 & 6 & 7 \\
\hline (1) Gyrodactylus major sp. n.* & \multicolumn{6}{|l|}{$\underline{0.00}$} \\
\hline (2) Gyrodactylus bueni sp. n.* & \multicolumn{6}{|c|}{$0.26 \underline{0.01}$} \\
\hline \multicolumn{7}{|c|}{ (3) Gyrodactylus scleromystaci sp. n.*0.54 0.46 $\underline{0.00}$} \\
\hline \multicolumn{7}{|c|}{ (4) Gyrodactylus sp. (from S. barbatus)* $0.440 .470 .72 \underline{0.03}$} \\
\hline (5) Gyrodactylus corydori ${ }^{+}$ & \multicolumn{6}{|c|}{$0.300 .290 .510 .35 \underline{0.00}$} \\
\hline (6) Gyrodactylus samirae ${ }^{+}$ & \multicolumn{6}{|c|}{$0.390 .340 .710 .360 .33 \underline{0.01}$} \\
\hline (7) Gyrodactylus superbus ${ }^{+}$ & \multicolumn{6}{|c|}{$0.320 .370 .570 .360 .16 \overline{0.32} 0.00$} \\
\hline
\end{tabular}

ported by phylogenetic analyses based on DNA sequences of the cytochrome oxidase II gene (COII) and ITS1-ITS2. The use of DNA markers independently has provided support for taxonomic identification of species of Gyrodactylus, but a combination of mitochondrial and nuclear DNA markers seems to be more consistent for the delimitation of species (sensu Hansen et al. 2006, Kuusela et al. 2008, Bueno-Silva et al. 2011).

Sequences of COII varied in length between and within species of Gyrodactylus, suggesting that this gene could contribute to population genetic studies. Interestingly, we have found the TTG start codon for COII gene of Neotropical species of Gyrodactylus, which is considered a novelty, given that only ATG start codon is known at present for cytochrome oxidase genes of Gyrodactylus (see Huyse et al. 2007, 2008, Plaisance et al. 2007).

The COI gene is most commonly used for the barcoding of species of eukaryotes (Hebert et al. 2003). This gene, however, is difficult to amplify successfully for several animal species (Bhadury et al. 2006, Moszczynska et al. 2009, Hoareau and Boissin 2010), including species of Gyrodactylus (see Meinilä et al. 2002, this study). Alternatively, the COII gene has been successfully used as a molecular marker in phylogenetic reconstructions and evolutionary studies for various species of animals (Spicer 1995, Adkins et al. 1996, Frati et al. 1997, Caterino and Sperling 1999, Pruess et al. 2000, Piaggio and Spicer 2001, Rawson and Burton 2006). Although the rate of nucleotide substitution of COII is higher than the COI in Gyrodactylus (Huyse et al. 2008), we found it easier to locate conserved regions of the mitochondrial genome to design primers to amplify and sequence COII than COI of Gyrodactylidae. The COII primers proposed herein may not be universal but the data suggest that COII could be used as an additional molecular marker for species of Gyrodactylidae and possibly other lineages of Monogenoidea.

The pairs of COII primers proposed herein provide consistent amplifications of the sampled specimens and the fragment depicts exceptional potential in the recognition of specific clusters. Thus, we propose the COII gene as an additional molecular marker for barcoding viviparous Gyrodactylidae. The fragment is likely useful for phyloge- 
netic, phylogeographic and other studies involving species of this lineage. In addition, the usefulness of the proposed primers may be more extensive than recognized herein. They were consistently efficient in amplifying and sequencing of members of several other families of Monogenoidea, including several species of Oligonchoinea (Bicotylophoridae, Diclidophoridae and Microcotylidae) and Polyonchoinea (Capsalidae, oviparous Gyrodactylidae and Udonellidae; data not shown). Occasionally, the COII primers fail to amplify DNA, but we have found that, at least for some species, this could be solved with the adjustment (e.g. lowering) of the annealing temperature in PCR.
Acknowledgements. We wish to thank the staff of the Laboratório de Ecologia Molecular e Parasitologia Evolutiva (LEMPE/UFPR), Rogério T. Vianna (FURG) and Jean Vitule (UFPR) for field and laboratory support, Haakon Hansen for a pre-submission review of the manuscript and the Programa de Pós-graduação em Zoologia (UFPR). We are grateful to the curators of the IPCAS, MZUSP, MNHN and HWML for their attention. The Conselho Nacional de Desenvolvimento Científico e Tecnológico (CNPq, Brazil) provided financial support for this study and granted support to M. Bueno-Silva and W. A. Boeger. The Instituto Brasileiro do Meio Ambiente e dos Recursos Naturais Renováveis (IBAMA, Brazil) granted the license for collection of biological material (license 087/2004, 10811/2007 and 11617/2008-2010).

\section{REFERENCES}

Adkins R.M., Honeycutt R.L., Disotell T.R. 1996: Evolution of eutherian cytochrome c oxidase subunit II: heterogeneous rates of protein evolution and altered interaction with cytochrome c. Mol. Biol. Evol. 13: 1393-1404.

Bakke T.A., Cable J., Harris P.D. 2007: The biology of gyrodactylid monogeneans: the "Russian doll-killers". Adv. Parasitol. 64: 161-376.

Bhadury P., Austen M.C., Bilton D.T., Lambshead P.J.D., Rogers A.D., Smerdon G.R. 2006: Development and evaluation of a DNA-barcoding approach for the rapid identification of nematodes. Mar. Ecol. Prog. Ser. 320: 1-9.

Boeger W.A., Kritsky D.C., Pie M.R. 2003: Context of diversification of the viviparous Gyrodactylidae (Platyhelminthes, Monogenoidea). Zool. Scr. 32: 437-448.

Boeger W.A., Vianna R.T., Thatcher V.E. 2006: Monogenoidea. In: J. Adis, J.R. Arias, G. Rueda-Delgado and K.M. Wantzen (Eds.), Amazon Fish Parasites. Vol. 1, Second edition. Pensoft Publishers, Sofia, pp. 42-116.

Bonfield J., Beal K., Cheng Y., Jordan M., Staden R. 1995: Staden Package version 2.0. World Wide Web electronic publication, staden.sourceforge.net, 12/2013.

Bueno-Silva M., Boeger W.A. 2009: Neotropical Monogenoidea. 53. Gyrodactylus corydori sp. n. and redescription of Gyrodactylus anisopharynx (Gyrodactylidea: Gyrodactylidae), parasites of Corydoras spp. (Siluriformes: Callichthyidae) from southern Brazil. Folia Parasitol. 56: 13-20.

Bueno-Silva M., Boeger W.A., Pie M.R. 2011: Choice matters: incipient speciation in Gyrodactylus corydori (Monogenoidea: Gyrodactylidae). Int. J. Parasitol. 41: 657-667.

Calendini F., Martin J.F. 2005: PaupUP v1.0.3.1. A free graphical frontend for PAUP DOS software. World Wide Web electronic publication, www.agromontpellier.fr/sppe/Recherche/ JFM/PaupUp/main.htm, 12/2013.

Caterino M.S., Sperling F.A. 1999: Papilio phylogeny based on mitochondrial cytochrome oxidase I and II genes. Mol. Phylogenet. Evol. 11: 122-137.

Cohen S.C., Kohn A. 2008: South American Monogenea - list of species, hosts and geographical distribution from 1997 to 2008. Zootaxa 1924: 1-42.

Cunningham C. 1997: Species variation within the internal transcribed spacer (ITS) region of Gyrodactylus (Monogenea: Gyrodactylidae) ribosomal RNA genes. J. Parasitol. 83: 215-219.

Cunningham C.O., McGillivray D.M., MacKenzie K., Melvin W.T. 1995a: Discrimination between Gyrodactylus salaris, $G$. derjavini and G. truttae (Platyhelminthes: Monogenea) using restriction fragment length polymorphisms and an oligonucleotide probe within the small subunit ribosomal RNA gene. Parasitology 111: 87-94.

Cunningham C.O., McGillivray D.M., MacKenzie K., Melvin W.T. 1995b: Identification of Gyrodactylus (Monogenea) species parasitising salmonid fish using DNA probes. J. Fish Dis. 18: 539-544.

Cunningham C.O., Mo T.A. 1997: Random amplified polymorphic (RAPD) analysis of three Norwegian Gyrodactylus salaris populations (Monogenea; Gyrodactylidae). J. Parasitol. 83: 311-314.

Dávidová M., Jarkovský J., Matějusová I., Gelnar M. 2005: Seasonal occurrence and metrical variability of Gyrodactylus rhodei Žitnan 1964 (Monogenea, Gyrodactylidae). Parasitol. Res. 95: 398-405.

Dmitrieva E., Dimitrov G. 2002: Variability in the taxonomic characters of Black Sea gyrodactylids (Monogenea). Syst. Parasitol. 51: 199-206.

EDGAR R.C. 2004: MUSCLE: multiple sequence alignment with high accuracy and high throughput. Nucleic Acids Res. 32: 1792-1797.

Ferraris C.J. 2007: Checklist of catfishes, recent and fossil (Osteichthyes: Siluriformes), and catalogue of siluriform primary types. Zootaxa 1418: 1-628.

Frati F., Simon C., Sullivan J., Swofford D.L. 1997: Evolution of the mitochondrial cytochrome oxidase II gene in Collembola. J. Mol. Evol. 44: 145-158.

Geets A., Appleby C., Ollevier F. 1999: Host-dependent and seasonal variation in opisthaptoral hard parts of Gyrodactylus cf. arcuatus from three Pomatoschistus spp. and G. arcuatus from Gasterosteus aculeatus: a multivariate approach. Parasitology 119: 27-40.

Hansen H., Bachmann L., Bakke T.A. 2003: Mitochondrial DNA variation of Gyrodactylus spp. (Monogenea, Gyrodactylidae) populations infecting Atlantic salmon, grayling, and rainbow trout in Norway and Sweden. Int. J. Parasitol. 33: 1471-1478.

Hansen H., Bakke T.A., Bachmann L. 2007a: DNA taxonomy and barcoding of monogenean parasites - lessons from Gyrodactylus. Trends Parasitol. 23: 363-367.

Hansen H., Bakke T.A., Bachmann L. 2007b: Mitochondrial haplotype diversity of Gyrodactylus thymalli (Platyhelminthes; Monogenea): extended geographic sampling in United Kingdom, Poland, and Norway reveals further lineages. Parasitol. Res. 100: 1389-1394. 
Hansen H., Martinsen L., Bakke T.A., Bachmann L. 2006: The incongruence of nuclear and mitochondrial DNA variation supports conspecificity of the monogenean parasites Gyrodactylus salaris and G. thymalli. Parasitology 133: 639-650.

HARRIS P.D. 1998: Extreme morphological variation between related individuals of Gyrodactylus pungitti Malmberg, 1964 (Monogenea). Syst. Parasitol. 39: 137-140.

Harris P.D., Shinn A.P., Cable J., Bakke T.A., Bron J.E. 2008: GyroDb: gyrodactylid monogeneans on the web. Trends Parasitol. 24: 109-111.

Hebert P.D.N., Ratnasingham S., de WaArd J.R. 2003: Barcoding animal life: cytochrome c oxidase subunit 1 divergences among closely related species. Proc. R. Soc. Lond. B Biol. Sci. 270: S96-S99.

Hoareau T.B., Boissin E. 2010: Design of phylum-specific hybrid primers for DNA barcoding: addressing the need for efficient COI amplification in the Echinodermata. Mol. Ecol. Resour. 10: 960-967.

Huson D.H., Scornavacca C. 2012: Dendroscope 3: An interactive tool for rooted phylogenetic trees and networks. Syst. Biol. 61: 1061-1067.

Huyse T., Buchmann K., Littlewood D.T. 2008: The mitochondrial genome of Gyrodactylus derjavinoides (Platyhelminthes: Monogenea) - a mitogenomic approach for Gyrodactylus species and strain identification. Gene 417: 27-34.

Huyse T., Plaisance L., Webster B.L., Mo T.A., Bakke T.A., Bachmann L., Littlewood D.T.J. 2007: The mitochondrial genome of Gyrodactylus salaris (Platyhelminthes: Monogenea), a pathogen of Atlantic salmon (Salmo salar). Parasitology 134: 739-747.

Huyse T., Volckaert F.A.M. 2002: Identification of a host-associated species complex using molecular and morphometric analyses, with description of Gyrodactylus rugiensoides $\mathrm{n}$. $\mathrm{sp}$. (Gyrodactylidae, Monogenea). Int. J. Parasitol. 32: 907-919.

Kohn A., Cohen S.C. 1998: South American Monogenea - list of species, hosts and geographical distribution. Int. J. Parasitol. 28: $1517-1554$

Kritsky D.C., Boeger W.A., Popazoglo F. 1995: Neotropical Monogenoidea. 22. Variation in Scleroductus species (Gyrodactylidea, Gyrodactylidae) from siluriform fishes of southeastern Brazil. J. Helminthol. Soc. Wash. 62: 53-56.

Kuusela J., Ziętara M.S., Lumme J. 2008: Description of three new European cryptic species of Gyrodactylus Nordmann, 1832 supported by nuclear and mitochondrial phylogenetic characterization. Acta Parasitol. 53: 120-126.

Malmberg G. 1970: The excretory systems and the marginal hooks as a basis for the systematics of Gyrodactylus (Trematoda, Monogenea). Ark. Zool. 23: 1-235.

Matějusová I., Gelnar M., McBeath A.J.A., Collins C.M., Cunningham C.O. 2001: Molecular markers for gyrodactylids (Gyrodactylidae: Monogenea) from five fish families (Teleostei). Int. J. Parasitol. 31: 738-745.

Meinilä M., Kuusela J., Ziętara M., Lumme J. 2002: Primers for amplifying $\sim 820 \mathrm{bp}$ highly polymorphic mitochondrial COI gene of Gyrodactylus salaris. Hereditas 137: 72-74.

Meinilä M., Kuusela J., Ziętara M.S., Lumme J. 2004: Initial steps of speciation by geographic isolation and host switch in salmonid pathogen Gyrodactylus salaris (Monogenea: Gyrodactylidae). Int. J. Parasitol. 34: 515-526.

Mo T.A. 1991a: Variations of opisthaptoral hard parts of Gyrodactylus salaris Malmberg, 1957 (Monogenea: Gyrodactylidae) on parr of Atlantic salmon Salmo salar L. in laboratory experiments. Syst. Parasitol. 20: 11-19.

Mo T.A. 1991b: Variations of opisthaptoral hard parts of Gyrodactylus salaris Malmberg, 1957 (Monogenea: Gyrodactylidae) on rainbow trout Oncorhynchus mykiss (Walbaum, 1792) in a fish farm, with comments on the spreading of the parasite in southeastern Norway. Syst. Parasitol. 20: 1-9.

Moszczynska A., Locke S.A, McLaughlin J.D., Marcogliese D.J., Crease T.J. 2009: Development of primers for the mitochondrial cytochrome c oxidase I gene in digenetic trematodes (Platyhelminthes) illustrates the challenge of barcoding parasitic helminths. Mol. Ecol. Resour 9: 75-82.

Olstad K., Bachmann L., Bakke T.A. 2009: Phenotypic plasticity of taxonomic and diagnostic structures in gyrodactylosiscausing flatworms (Monogenea, Platyhelminthes). Parasitology 136: $1305-1315$.

Piaggio A.J., Spicer G.S. 2001: Molecular phylogeny of the chipmunks inferred from mitochondrial cytochrome $b$ and cytochrome oxidase II gene sequences. Mol. Phylogenet. Evol. 20: $335-350$.

Plaisance L., Huyse T., Littlewood D.T., Bakke T.A., BachMANN L. 2007: The complete mitochondrial DNA sequence of the monogenean Gyrodactylus thymalli (Platyhelminthes: Monogenea), a parasite of grayling (Thymallus thymallus). Mol. Biochem. Parasitol. 154: 190-194.

Popazoglo F., Boeger W.A. 2000: Neotropical Monogenoidea 37. Redescription of Gyrodactylus superbus (Szidat, 1973) comb. n. and description of two new species of Gyrodactylus (Gyrodactylidea: Gyrodactylidae) from Corydoras paleatus and C. ehrhardti (Teleostei: Siluriformes: Callichthyidae) of southern Brazil. Folia Parasitol. 47: 105-110.

Posada D. 2008: jModelTest: Phylogenetic model averaging. Mol. Biol. Evol. 25: 1253-1256.

Pruess K.P., Adams B.J., Parsons T.J., Zhu X., Powers T.O. 2000: Utility of the mitochondrial cytochrome oxidase II gene for resolving relationships among black flies (Diptera: Simuliidae). Mol. Phylogenet. Evol. 16: 286-295.

Rawson P.D., Burton R.S. 2006: Molecular evolution at the cytochrome oxidase subunit 2 gene among divergent populations of the intertidal copepod, Tigriopus californicus. J. Mol. Evol. 62: $753-764$

SPICER G.S. 1995: Phylogenetic utility of the mitochondrial cytochrome oxidase gene: molecular evolution of the Drosophila buzzatii species complex. J. Mol. Evol. 41: 749-759.

Swofford D.L. 2001: PAUP: Phylogenetic analysis using parsimony (and others methods). Version 4.0b10. Sinauer Associates, Sunderland.

Tamura K., Peterson D., Peterson N., Stecher G., Nei M., Kumar S. 2011: MEGA5: Molecular Evolutionary Genetics Analysis using maximum likelihood, evolutionary distance, and maximum parsimony methods. Mol. Biol. Evol. 28: 27312739.

Ziętara M.S., Arndt A., Geets A., Hellemans B., Volckaert F.A.M. 2000: The nuclear rDNA region of Gyrodactylus arcuatus and G. branchicus (Monogenea: Gyrodactylidae). J. Parasitol. 86: 1368-1373.

Ziętara M.S., Lumme J. 2003: The crossroads of molecular, typological and biological species concepts: two new species of Gyrodactylus Nordmann, 1832 (Monogenea: Gyrodactylidae). Syst. Parasitol. 55: 39-52. 